\title{
User Conceptions of Trustworthiness for Digital Archival Documents
}

\author{
Devan Ray Donaldson \\ University of Michigan School of Information, 3349C North Quad, 105 South State Street, Ann Arbor, MI, \\ 48109. E-mail: devand@umich.edu \\ Paul Conway \\ University of Michigan School of Information, 4427 North Quad, 105 South State Street, Ann Arbor, MI 48109. \\ E-mail: pconway@umich.edu
}

\begin{abstract}
Trust is the most important characteristic of digital repositories designed to hold and deliver archival documents that have persistent value to stakeholders. In theoretical models of trust in information, the concept of trustworthiness is emerging as both fundamentally important and understudied, particularly in the domain of digital repositories. This article reports on a qualitative study designed to elicit from groups of end users components of trustworthiness and to assess their relative importance. The study draws on interview data from 3 focus groups with experienced users of the Washington State Digital Archives. Utilizing thematic analysis and micro-interlocutor analysis to examine a combination of interview transcripts and video recordings, the study provides a realistic picture of the strength and character of emergent themes that underpin the more general concept of trustworthiness. The study reinforces the centrality of trustworthiness at the individual document level, but calls into question the formulation of trustworthiness as a concept in Kelton, Fleischmann, and Wallace's (2008) Integrated Model of Trust in Information.
\end{abstract}

\section{Introduction}

Trust is the most fundamental but perhaps least well understood property of digital repositories that hold and preserve archival documents. For at least 15 years, information scientists, digital curators, archivists, and computer scientists have worked successfully to design and construct robust, standards-oriented storehouses for digital archival

Received October 8, 2013; revised May 1, 2014; accepted May 2, 2014

(C) 2015 ASIS\&T • Published online in Wiley Online Library (wileyonlinelibrary.com). DOI: 10.1002/asi.23330 documents. As these "Trusted Digital Repositories" (International Organization for Standardization, 2012) ${ }^{1}$ scale in size and complexity, they are becoming "sources of first resort" for increasingly diverse populations of users, ranging from scholars, students, government and corporate administrators, investigators from the private sector, genealogists, and the general curious public. Scholarship across multiple disciplines has demonstrated that trust in a digital repository tends to originate with organizational branding, surrounds and envelops the "control zone" of the managed digital space (Atkinson, 1996), and so resides primarily at the collective level of the repository (Waters \& Garrett, 1996). In spite of its conceptual centrality, little research has investigated trust in the documentary contents

${ }^{1}$ For over a decade, the digital preservation and curation research communities have worked to develop standards for Trusted or Trustworthy Digital Repositories (TDRs). The motivation for this development comes from recognition among digital preservation and curation researchers and practitioners that repositories should not simply assert that any given repository is capable of preserving digital information. Instead, repositories should prove that they have the capacity to preserve digital information for the long term. According to the Research Libraries Group (RLG)/Online Computer Library Center (OCLC) Working Group on Digital Archive Attributes (WGDAA) (2002), a Trusted Digital Repository is "one whose mission is to provide reliable, long-term access to managed digital resources to its designated community, now and in the future" (p. 5). For more information on the concept of a TDR, consult RLG/OCLC WGDAA (2002) and the international standard for audit and certification of TDRs-ISO 16363 (International Organization for Standardization, 2012). In this study, the Washington State Digital Archives (WADA) is considered TDR-like, because although WADA has not yet been formally certified as a TDR, the authors of this study argue that, if one compares WADA's practices and procedures with criteria for TDRs as specified in ISO 16363, WADA would likely attain TDR status if it underwent formal certification processes. 


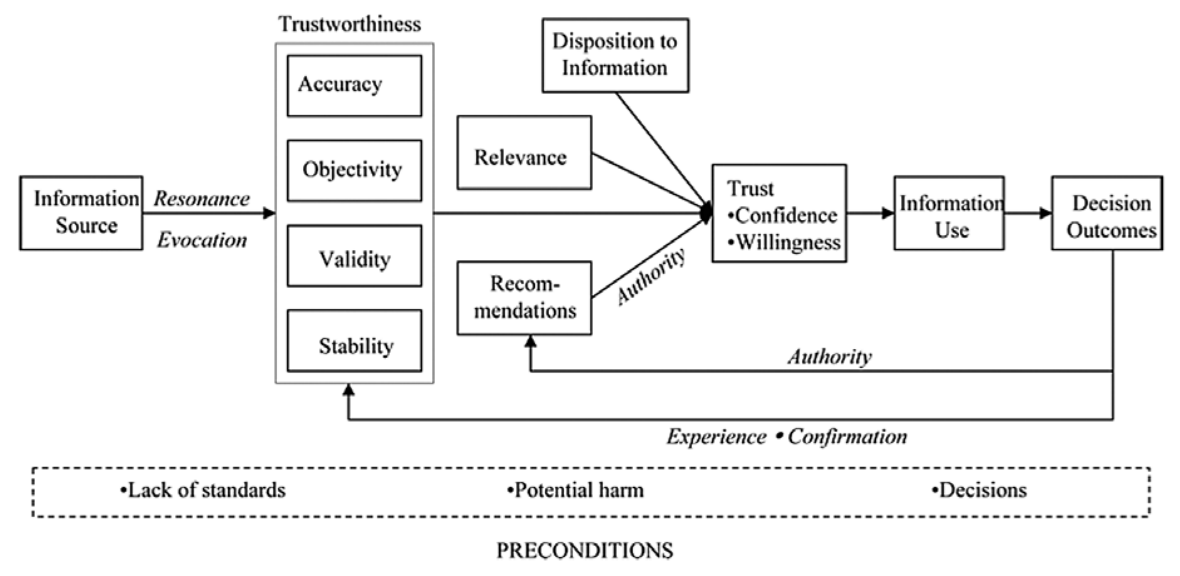

FIG. 1. Kelton et al.'s (2008, p. 369) Integrated Model of Trust in Information.

of repositories as conceived by the "Designated Communities" (Consultative Committee for Space Data Systems, $2002)^{2}$ of users that the repository is intended to serve.

This article reports on the first part of a two-phase investigation into user conceptions of trustworthiness for digital archival documents housed in a large, heterogeneous, government-run digital repository. The goal of the overall study is to construct and test scale of trustworthiness that is grounded in perceptions held by a particular "designated community" in the context of a well-managed, large-scale digital repository. The point of departure for the study is Kelton, Fleischmann, and Wallace's (2008) Integrated Model of Trust in Information, which provides a testable framework for the elements of trust. The first step of the overall project involves eliciting perspectives on trustworthiness from user populations who depend on digital documents to satisfy particular information needs. This article positions the design of the first-step study in the research literatures of digital curation, web credibility, and archival science, summarizes the focus group method employed to solicit perceptions of trustworthiness, and presents findings from the interview populations. Specifically, the research utilizes semistructured focus group discussion and card-sorting exercises with 22 genealogists who regularly use documents preserved by the Washington

\footnotetext{
${ }^{2}$ According to the Consultative Committee for Space Data Systems (CCSDS) (2002), a designated community is "an identified group of potential Consumers who should be able to understand a particular set of information. The Designated Community may be composed of multiple user communities" (p. 1-10). In addition, the CCSDS specifies that digital repository managers monitor their designated communities to make sure that over time the information preserved in digital repositories remains understandable to its designated community members. For more on the concept of a designated community, consult CCSDS (2002), RLG/OCLC WGDAA (2002), and International Organization for Standardization (2012). In this study, genealogists are the designated community under investigation because the WADA staff has identified genealogists as its largest designated community of users.
}

State Digital Archives (WADA). The interviews uncover how this "designated community" conceptualizes the trustworthiness of discrete documents delivered through a managed digital repository. The net result is a framework of insights that specifies the subelements of a multifaceted conception of trustworthiness.

We assume that users of digital repositories conceptualize document trustworthiness and are capable of articulating their perspectives on the concept. Two questions underpin this assumption and guide the research presented in this article:

Research Question 1: How do members of a designated community conceptualize trustworthiness for documents they find in a digital repository?

Research Question 2: To what extent do designated community members' conceptions of document trustworthiness compare with the conception of trustworthiness in Kelton et al.'s (2008) Integrated Model of Trust in Information?

\section{Scholarship on Trustworthiness}

The information science literature casts the concept of "trustworthiness" as a multifaceted property of an aggregated source, regardless of whether that source is a website (Fogg, 2003; Metzger, 2007) or the archived content delivered through a web browser (Duranti, 1995; MacNeil, 2000; MacNeil \& Mak, 2007; Hilligoss \& Rieh, 2008). An important exception to the general focus on repository trust is the "information-centric" approach to trust pioneered by Kelton et al. (2008). Their Integrated Model of Trust in Information (Figure 1) is derived from a synthesis of highly selective research literature on interpersonal trust. The model posits trustworthiness as one of four clusters of factors (along with disposition, relevance judgments, and the authority of recommendations) that lead a user from an encounter with an information source to the confidence and willingness to make use of that source. The Kelton model proposes that the trustworthiness of information is not necessarily a fixed property of a source but rather a judgment made by users on 
a number of dimensions-later confirmed through experience. The model also has the potential to contextualize user perceptions of trustworthiness at the document level within a thorough web of complex direct and indirect relationships. The labels and arrows pointing to and from Trustworthiness in Figure 1 denote the relationships between Trustworthiness and other constructs, indicating that the development of trustworthiness perception is a looped process with inputs and outputs reinforcing trustworthiness perception.

The Trustworthiness component in the Kelton model ( $\mathrm{p}$. 370 ) is the collective outcome of user perceptions of four properties of an information source: accuracy, objectivity, validity, and stability, defined as:

- Accuracy: the extent to which information is free from error (plus believability, coverage, and currency not pictured in the model).

- Objectivity: the balance of content.

- Validity: the use of responsible and accepted practices such as the soundness of the methods used, the inclusion of verifiable data, and the appropriate citation of sources.

- Stability: the persistence of information, both its presence and contents.

Unlike other efforts in the information science literature to define trust in information (Lucassen \& Schraagen, 2011, 2012; Lucassen, Muilwijk, Noordzij, \& Schraagen, 2013), the Kelton model is an admirable attempt to construct a model that can generate testable hypotheses. Indeed, near the end of their article the authors propose a host of research areas and questions that they believe derive directly from the structure of the model. First among their recommendations is developing "an instrument for measuring trust in information" (p. 371).

The problem with the Kelton model, one that motivates the research reported here, concerns the specification of "trustworthiness." The model maps judgments of personal competence to no fewer than four complex and somewhat conflated concepts under the term "accuracy," including accuracy itself, believability, coverage, and currency. These terms are but a small subset of the many characteristics of information sources covered in the information quality literature (Knight, 2008). Scholars across a number of associated disciplines also have wrestled with how to operationalize the components of this abstract notion. Any measure of trustworthiness should seek to reconcile this diverse research, if for no other reason than increasing the usefulness of a trustworthiness measure.

This study uses the Kelton model as a point of departure but also builds on an information science perspective of trustworthiness that lies at the intersection of research in archival science and web credibility. The archival science literature includes definitions of trustworthiness that influence digital archivists' conceptualizations for digital repositories. The web credibility literature, in contrast, focuses most directly and purposefully on how end users conceptualize trustworthiness.

\section{Trustworthiness in Archival Science Research}

Little research exists on how end users might apply the concept of trustworthiness to archival documents delivered digitally within a preservation context. Hedstrom and Lee's (2002) framework of "significant properties" lays a foundation for such research, while more recent research is beginning to advance an understanding of user trust at the archival repository level. Yoon (2014) investigates the users of social science data archives, finding that trust may arise from the lack of deceptive repository practices and be formed in part through iterative experience rather than through the assessment of retrieved documents. The ongoing work of Yakel, Faniel, Kriesberg, and Yoon (2013) is exploring data reuse by archaeologists and quantitative social scientists, with trust also lodged in the larger context of the transparent data repository, rather than at the document level.

In the domain of digital libraries, the notion of trust is elusive. Lynch (2000, p. 33) notes that "it is much easier to devise abstract definitions than testable ones." As an alternative, some digital repository developers have also seized upon transparency as the measure of trust in long-term preservation: "It is important for large digital libraries to demonstrate they are a viable, trustworthy resource by making their efforts clear and by publishing their policies" (Henry, 2012 , p. 14). Gladney (2009, p. 416) pushes repository trust well beyond the realm of policy into the technical infrastructure of the underlying document system. He argues that the two keys to trustworthy digital objects are the documentation of provenance and protection from tampering through "cryptographic message authentication codes." Price and Smith (2011) also locate trust in the "complex expert system," rather than in the explicit perspectives of end users. In this and similar work on digital libraries, end users seem to be the silent partners in trustworthiness, rarely invoked directly or relegated to components of the repository system itself.

In archival science, Hedstrom and Lee (2002) argue and partially demonstrate that trust may be embedded in the properties of the archival document, rather than in the perceptions of those who use it. Yeo (2010) builds on this idea in his thorough assessment of how document properties contribute to the uniqueness and originality of archival documents and help sort out the distinctive qualities of digital archival documents. In his recent work on trust in the context of archival databases, Yeo (2013, pp. 225-226) argues for transparent communication of information on the provenance, or the chain of custody, between the system and the end user. But ultimately, Yeo's investigation stops short of validating the perceptions of those called upon to trust and falls back on the value of the expert mediation of archivists to guarantee trust.

In their classic and frequently invoked assessments, Duranti (1995) and MacNeil (2000) define trustworthiness of a document in terms of three general properties: reliability, authenticity, and genuineness. A reliable document is "capable of standing for the facts to which it attests" and is 
assessed in terms of the document's "completeness and controlled procedure of creation" (Duranti, p. 8). An authentic document is, ontologically speaking, "what it purport[s] to be" (Duranti) or "is what it claims to be" (MacNeil). A genuine document, according to Duranti, is one whose content is truthful. Coming full circle, MacNeil and Mak (2007) review the concept of authenticity from an interdisciplinary perspective and conclude by lodging archival authenticity at the document level as a "trustworthy statement of fact."

Extending an argument that trustworthiness exists perhaps primarily at the document level, Duranti, Suderman, and Todd (2008) somewhat circuitously define a digital record as one that is both reliable and accurate. "Reliability is the trustworthiness of a record's content," they claim, "because by definition, the content of a reliable record is trustworthy, and trustworthy content is, in turn, predicated on accurate data, it follows that a reliable record is also an accurate record" (p. 667). These definitions partition trustworthiness into multiple components, some having to do with a document "as a document" and others having to do with a document "as content or information." The archival science perspective on trustworthiness has tended to treat the end user, when invoked at all, as the recipient of "propertied" information, rather than as participants in the formation of trustworthiness.

Although archivists tend to conceptualize document trustworthiness in terms of authenticity, research in an archival science context suggests that users may not be particularly concerned about trustworthiness in the same way. In one study (Meijer, 2003), no one explicitly charged with document accountability questioned the authenticity of the digital records generated by their organizations. Similarly, Duff, Craig, and Cherry (2004) found that less than one fifth (108 of 600) of the historians they studied had ever questioned the authenticity of an archival source while conducting research. Meijer (2003) found that one important reason that users do not question the authenticity of archival documents delivered digitally is the lack of evidence that digitization led to incomplete reconstructions of facts. In an important controlled experiment, Hedstrom, Lee, Olson, and Lampe (2006) found that undergraduate and graduate students assumed the documents they used were authentic "because they thought there was little or no incentive for anyone to tamper with them, because they conformed to their prior notion of what an authentic document ought to look like, or because [the researchers] told them that the documents came from the Bentley [Historical] Library" (pp. 184-185). Cumulatively, these studies suggest that users assume authenticity unless there is reason to suspect otherwise, particularly when they do not perceive anything suspicious about the documents and they understand that the documents are being preserved in a digital archive.

Research with users in an archival science context also suggests that users find it difficult to assess authenticity and employ a variety of strategies to address any concerns they may have. For example, Zhou (2005) found that undergraduate and graduate students have difficulty assessing authenticity because, according to them, "advanced software can change the appearance of any item on the computer screen" (p. 9). Similarly, Hedstrom et al. (2006) found that most of their participants were unsure about whether the digital documents they used were "originals." In Duff et al. (2004) participants questioned the authenticity of a document "when they suspected either the source of the document, or doubted the identity of the named or implied creator of the document, or were otherwise suspicious of its genuineness" (p. 68). To address these concerns, respondents reported that they would analyze the source in its context of contemporary materials, track clear lines of provenance from the source to the archives, seek to understand the criteria for selecting material for copy formats, and confirm contemporary statements and their own hypotheses in similar records or even contemporary duplicates of records (p. 69). Failing this sort of "forensic" examination of archival documents themselves, Duff et al. found that end users rely on human agents (archivists) to assuage their concerns, because study participants assumed that the archivists have established and explained the provenance, and if the evidence participants have at their disposal seems contradictory, the archivist will be able to clarify reliability concerns. Duranti (2009) reinforces the central role of the archivist as the mediator of trust and establishes a complex knowledge structure to support this responsibility. Taken together, the relatively few studies of end users in the context of digital archival documents suggest that end users' conceptualizations of the components of trustworthiness remain elusive and underspecified.

\section{Trustworthiness in the Web Credibility Research Literature}

In over a decade of research on the credibility of the World Wide Web (Flanagin \& Metzger, 2000; Fogg, 2003; Rieh \& Danielson, 2007; Rieh, 2010; Rieh, Kim, Yang, \& St. Jean, 2010), trustworthiness has emerged as a critical element of the overall concept of credibility. In contrast with archival science, whereby trustworthiness is vested in the archival document, web credibility research locates document trustworthiness as grounded in the perceptions of end users. Hilligoss and Rieh (2008) conclude their study by defining "information [a]s trustworthy when it appears to be [emphasis added] reliable, unbiased, and fair" (p. 1469). Implicit in their definition is the idea that it is users to whom information would appear (or not appear) to be reliable, unbiased, and fair. More explicitly, Flanagin and Metzger (2008) define trustworthiness as "a receiver judgment based primarily on subjective factors" (p. 8). This shift in emphasis from objective property to perceived value opens an opportunity to create a conceptual bridge between the subjective and the objective.

Qualitative research conducted in the field of web credibility suggests that trustworthiness, from the end user's perspective, is a multifaceted construct. In Rieh (2002), participants expressed their views of the trustworthiness of 
information they encountered on the web using phrases such as "I trust it, trustworthy, believe in, confidence that this is true, seems real, [and] faith in the quality," suggesting that users conceptualize trustworthiness in terms of believability, perceived truthfulness, authenticity, and high (or at least sufficient) quality (p. 153). In St. Jean, Rieh, Yakel, and Markey (2011), heavy users of institutional repositories interpreted the term trustworthy "in many different ways such as factual, legitimate, reliable, reputable, professional, comprehensive, updated, and verifiable" (p. 33). Metzger, Flanagin, and Medders (2010) found that participants in a focus group study consider information they perceive as objective as much more trustworthy than information they consider subjective. Taken together, these qualitative web credibility research studies suggest that users are capable of articulating the complexity of their conceptualization of trustworthiness. There seems an opportunity for research that leverages methods and theoretical frameworks developed in web credibility to inform our understanding of user trustworthiness perception for archival documents delivered digitally.

\section{Methods}

To address the research questions-How do members of a designated community conceptualize trustworthiness for documents they find in a digital repository? To what extent do designated community members' conceptions of document trustworthiness compare with trustworthiness conception in Kelton et al.'s (2008) Integrated Model of Trust in Information? - the first phase of the overall study used two methods in a task-sensitive, focus group setting. Qualitative data from interactive, moderated interviews create a foundation of expression from end users about how they conceptualize the idea of "trustworthiness." Quantitative data from the card-sorting exercises immediately following group discussion established the boundaries and priorities of concepts that may collectively define trustworthiness within a specific population of users. The focus group investigation sought to accomplish the important goals of: identifying points of convergence and divergence in the elements of trustworthiness identified in the Kelton model, and exploring how end users cluster the subelements of trustworthiness, after the "priming effect" of group discussion.

\section{The Washington State Digital Archives (WADA) as the Primary Site of Study}

The WADA is the primary site of the research project. WADA is a heavily utilized digital cultural heritage resource, developed and maintained at taxpayer expense as a mechanism for providing open, public access to archives and records of the State of Washington. Approximately 500,000 people visit the home page of WADA per year, with thousands of unique visitors per month. WADA has a strong and explicit mission statement that focuses on making preserved digital information accessible to users (Washington
State Archives-Digital Archives, 2013). Also, WADA conforms in principle to the requirements of a Trusted Digital Repository (TDR). It abides by leading best practices and standards for organizational infrastructure, digital object management, and technical infrastructure, including security issues, consistent with the International Organization for Standardization's specifications, despite not being formally certified as a TDR as of the time of this study (T.S. Badger, personal communication, March 8, 2013).

\section{Study Population and Recruitment}

This study focuses on experienced genealogists because this population of users represents WADA's largest designated community (T.S. Badger, personal communication, March 8, 2013). Also, based on WADA's download statistics, genealogical records are among WADA's most highly downloaded records. For these designated community members, most of the records they utilize are digitized records available for download in JPEG format accompanied by transcriptions. In some cases, only the digitized record is available, and in other cases, only the transcribed version is available. The information-seeking behavior of genealogists has been a topic of research in archival science (Duff \& Johnson, 2003; Yakel, 2004), as has the ways in which genealogists make use of the documents they find to construct a narrative (Yakel \& Torres, 2007). The gap between research on genealogists' information-seeking behavior and the ways genealogists use the documents they find involves the "decision to use"; trustworthiness is central to that decision.

The staff of WADA helped build a participant pool using two methods. First, WADA staff posted messages on their researcher-oriented listservs inviting users to participate in the focus groups, and to contact us directly expressing interest. Second, WADA staff enabled a pop-up message inviting users to participate in the focus groups to everyone who visited the WADA homepage during a 2 -week period. The message included a link to a form that allowed prospective participants to indicate their primary reason for visiting the WADA website (business, genealogy, historical research, local government, title searches, or other), and to provide contact information. After screening for people who were genealogists and who were available on one of the planned days/times of the focus groups, 22 participants were successfully recruited using both of these methods, and clustered into three groups-seven, seven, and eight participants.

The size of each focus group as well as the total number of focus groups in this study are consistent with recommendations in the focus group literature (Stewart \& Shamdasani, 1990; Morgan, 1997; Stewart, Shamdasani, \& Rook, 2007; Krueger \& Casey, 2009). For example, according to Stewart et al. (2007), "most focus groups are composed of six to twelve people," and, "when the population of interest is relatively homogeneous and the research question is relatively simple, a single group may be sufficient. . . . Most 
focus group applications involve more than one group, but seldom more than three or four groups" (p. 58). The three focus groups in this study were homogeneous; every participant self-reported that he was a genealogist who regularly used WADA. Nearly all participants reported using similar types of digitized archival documents (e.g., birth, death, and marriage records) and having similar information needs (e.g., conducting family history research for themselves or others). Also, the research questions were simple; they focused on participants' document trustworthiness perception for digitized archival documents found in WADA.

\section{Focus Group Settings and Procedures}

Since WADA users are geographically dispersed, each focus group took place at a different location to make it easier for users to participate in the study. The focus group sessions were conducted in private conference rooms over a period of 3 days during the month of June, 2013. The first focus group (FG1) took place at the Washington State Archives-Digital Archives in Cheney, WA; the second focus group (FG2) took place at the Washington State Archives in Olympia, WA; and the third focus group (FG3) took place at the Puget Sound Regional Archives in Bellevue, WA. Identical procedures were followed for all three group interviews, following guidance in Krueger (1998) and Stewart et al. (2007) for selecting a moderating team, pilot testing the focus group guide, preparing the rooms for the focus groups, and moderating the focus groups. For each session, one moderator and one assistant moderator were present. Participants were provided lunch as a partial incentive for participation. Each focus group lasted $\sim 2$ hours.

Each participant completed a presurvey (Appendix A1) that included questions related to study participants' Internet usage, participants' WADA usage, and demographics. Then, using the focus group guide (Appendix A2), the moderator asked four questions on: (1) the nature and purposes of the documents used; (2) user perceptions of trustworthiness for the documents found; (3) examples of documents found that are perceived as trustworthy; and (4) any circumstances for questioning the trustworthiness of documents in WADA. During the second part of the session, participants broke into pairs or trios to complete a card-sorting exercise in which they grouped trustworthiness attributes identified in the Kelton model in terms of their importance to them.

\section{Data Analysis}

To analyze the resulting focus group data, we conducted thematic analysis ${ }^{3}$ (Boyatzis, 1998; Braun \& Clarke, 2006;

${ }^{3}$ According to Boyatzis (1998), "thematic analysis is a process for encoding qualitative information. ... This may be a list of themes; a complex model with themes, indicators, and qualifications that are causally related; or something in between these two forms. A theme is a pattern found in the information that at minimum describes and organizes possible observations or at the maximum interprets aspects of the phenomenon" (pp.
Guest, MacQueen, \& Namey, 2012). Specifically, we executed the guidelines for thematic analysis in Braun and Clarke (2006), which involve the following six phases: (1) familiarizing yourself with the data, (2) generating initial codes, (3) searching for themes, (4) reviewing themes, (5) defining and naming themes, and (6) producing the report:

- Regarding Phase 1, we familiarized ourselves with the data by collecting the data ourselves and afterwards watching the video recordings of each focus group multiple times, so that ideas and identification of possible patterns could be shaped as we listened to what the study participants were saying and watched what they were doing. We also transcribed the video recordings as a way to further familiarize ourselves with the data, providing a verbatim account of all utterances, while retaining the information we needed in a way which was true to its original nature (Braun \& Clarke, 2006, p. 88).

- Regarding Phase 2, our coding was influenced by the fact that some of our themes were theory-driven and others were data-driven. Codes pertaining to our Kelton-based themes involved theoretical thematic analysis, where "analysis would tend to be driven by the researcher's theoretical or analytic interest in the area, and is thus more explicitly analyst driven" (Braun \& Clarke, 2006, p. 84). In particular, we coded the data with the specific definitions of the components of trustworthiness as defined by the Kelton model. In contrast, our Emergent themes were data-driven themes, which represent a form of inductive analysis whereby we coded the data "without trying to fit [them] into a pre-existing coding frame, or [our own] analytic preconceptions" (Braun \& Clarke, 2006, p. 83). Initially, we coded the data manually; afterwards we coded the data using NVivo 10.0 software. In each instance,

vi-vii). According to Braun and Clarke (2006), "a theme captures something important about the data in relation to the research question, and represents some level of patterned response or meaning within the data set," and, "the 'keyness' of a theme is not necessarily dependent on quantifiable measures-but rather on whether it captures something important in relation to the overall research question" (p. 82). They also add that "researcher judgment is necessary to determine what a theme is" (p. 82), because the amount of times a theme is or is not mentioned by any particular participant or group of participants may or may not be what determines the importance of a theme, as much as the identification of a theme in relation to the purposes of the research and the research questions. Part of thematic analysis involves determining the prevalence of themes. According to Braun and Clarke, while there is no right or wrong method for determining the prevalence of a theme during thematic analysis, researchers should make explicit the ways in which they define prevalence. We used micro-interlocutor analysis to operationalize the prevalence of the themes we identified during thematic analysis both within and across the focus groups. Table 1 offers a visual representation of the prevalence of each of the themes that we identified that were relevant to our research questions. For example, during discussion all seven participants in the first focus group (FG1), all seven participants in the second focus group (FG2), and all eight participants in the third focus group (FG3) made significant statements or expressed nonverbal communication in support of the Emergent Theme Authenticity, as shown in Table 1. In contrast, during discussion no participants in any of the focus groups provided statements in support of or in disagreement with the Kelton-based Theme Objectivity. Notwithstanding, Objectivity is still listed as a Kelton-based theme in this study because of its importance with respect to the purpose of the research and the research questions, in particular Research Question 2. It was important to demonstrate the extent to which Objectivity (as well as all of the other Kelton-based themes) was relevant in the context of our data set. 
we worked systematically through the entire data set, "giving full and equal attention to each data item," identifying interesting aspects in the data items that later formed the basis of repeated patterns (themes) across the data set (Braun \& Clarke, 2006, p. 89). Manually, we coded the data by writing notes on the transcripts we analyzed and using highlighters to indicate potential patterns. We then used NVivo 10.0 to create nodes corresponding to each code, and we color-coded each node to indicate potential patterns. We coded for as many potential themes/patterns as possible and we coded individual data items inclusively, keeping "a little of the surrounding data if relevant," so that context could be retained for each data item (Braun \& Clarke, 2006, p. 89). We also coded data items in as many different themes as they fit into, because some of the participants' responses addressed multiple themes.

- Regarding Phase 3, we focused the analysis at the broader level of themes, rather than codes, which involved sorting the different codes into potential themes, and collating all the relevant coded individual data items within the identified themes (Braun \& Clarke, 2006, p. 89). We analyzed our codes and considered how different codes could combine to form an overarching theme. We considered the relationships among the codes and themes, resulting in a collection of candidate themes and all the data that were coded in relation to them (Braun \& Clarke, 2006, pp. 89-90).

- Regarding Phase 4, we reviewed our themes by refining the set of candidate themes. We discarded candidate themes for which there was inadequate empirical support (i.e., a lack of supporting quotations), collapsed themes that were similar enough to be considered one theme, and broke themes that needed to be broken down into separate themes. We also reviewed and refined our themes on two levels. Regarding the first level, we reviewed all of the individual data items we had coded by reading those coded data and considering whether they appeared to form a coherent pattern. Afterwards, we considered the validity of individual themes in relation to the data set, examining whether the candidate themes accurately reflected the meanings evident in the data set as a whole. We reread the entire data set for two purposes: "to ascertain whether the themes "work' in relation to the data set," and "to code any additional data within themes that ha[d] been missed in earlier coding stages" (Braun \& Clarke, 2006, p. 91). We kept coding the data until themes were reoccurring and no new themes were identified in the context of the data set.

- Regarding Phase 5, we defined and further refined the themes we presented in our analysis and analyzed the data within them. Specifically, we identified the "essence" of what each theme was about and determined what aspect of the data each theme captured (Braun \& Clarke, 2006, p. 92). We went back to the collated data items for each theme and organized them into a coherent and internally consistent account, with accompanying narrative (Braun \& Clarke, 2006, p. 92). We analyzed the content of each coded data item to "identify what [wa]s of interest about them and why" (Braun \& Clarke, 2006, p. 92). In addition, we wrote a detailed analysis for each theme, considering how they related to the broader overall story we were telling about our data in relation to the research questions (Braun \& Clarke, 2006, p. 92). We considered each theme in relation to the others, developing concise names for the themes.

- Regarding Phase 6, we produced a report of our thematic analysis. We chose what we thought were particularly illustrative examples, which captured the essence of the point we were demonstrating regarding each theme. We also sought to embed illustrative quotations "within an analytic narrative that compellingly illustrates the story" we were telling about our data, having the analytic narrative "go beyond description of the data, and make an argument in relation to [our] research question[s]" (Braun \& Clarke, 2006, p. 93).

In addition, the focus group data were analyzed using micro-interlocutor analysis (Onwuegbuzie, Dickinson, Leech, \& Zoran, 2009). In this analysis technique, "meticulous information about which participant responds to each question, the order in which each participant responds, response characteristics, the nonverbal communication used, and the like is collected, analyzed, and interpreted" (p. 1). For each of the themes in this study, we applied microinterlocutor analysis by:

- providing verbatim statements made by focus group participants,

- delineating information about the number of members who appeared to be part of the consensus from which the category or theme emerged, and

- specifying the number of members who appeared to represent a dissenting view (if any) as well as how many participants did not appear to express any view at all.

This type of data analysis was conducted to avoid overstating the amount of consensus among participants within and across the focus groups for any particular theme while also being transparent about issues of nonresponse. In addition, we applied micro-interlocutor analysis to the transcribed verbal expressions by extracting from the video recording of each session information about participants' nonverbal communication - including chronemic (i.e., use of pacing of speech and length of silence in conversation), paralinguistic (i.e., all variations in volume, pitch, and quality of voice), and kinesic (i.e., body movements or postures) expressions-and incorporating these data alongside the verbal data (Onwuegbuzie et al., 2009, p. 10). The cardsorting data were analyzed using procedures in Fincher and Tenenberg (2005), specifically looking for commonality of criteria and their distribution across the study population.

\section{Findings}

The findings are organized into two sections. The first section focuses on participants' conceptualizations, through both narrative and card-sorting exercises, of trustworthiness in comparison with conceptualizations in Kelton et al. (2008). The second part discusses participants' conceptualizations of trustworthiness that are not modeled in Kelton, but that participants elicited. Both sections utilize passages from the focus group transcripts to provide illustrative examples of the themes. In addition, selective examples of nonverbal communication pertaining to the themes is presented and discussed alongside verbal data. Table 1 summarizes the results of micro-interlocutor analysis, showing the 
TABLE 1. Summary of group consensus on trustworthiness conceptualization.

\begin{tabular}{|c|c|c|c|c|c|c|}
\hline & FG1-A/SA & FG1-NR & FG2-A/SA & FG2-NR & FG3-A/SA & FG3-NR \\
\hline \multicolumn{7}{|l|}{ Kelton-based themes } \\
\hline Accuracy & 5 & 2 & 6 & 1 & 4 & 4 \\
\hline Believability & 2 & 5 & 5 & 2 & 1 & 7 \\
\hline Coverage & N/A & N/A & 4 & 3 & N/A & N/A \\
\hline Currency & N/A & N/A & N/A & N/A & N/A & N/A \\
\hline Objectivity & N/A & N/A & N/A & N/A & 3 & 4 \\
\hline Stability & 1 & 6 & N/A & N/A & 4 & 4 \\
\hline Validity & N/A & N/A & 5 & 2 & 2 & 6 \\
\hline \multicolumn{7}{|l|}{ Emergent themes } \\
\hline Authenticity & 7 & 0 & 7 & 0 & 8 & 0 \\
\hline Inaccurate/Trustworthy & 2 & 5 & $4 *$ & 2 & $4^{*}$ & 2 \\
\hline First-hand/Primary & 4 & 3 & 5 & 2 & 4 & 4 \\
\hline Legibility/Readability & 1 & 6 & $2 *$ & 4 & 4 & 4 \\
\hline Form & N/A & N/A & 6 & 1 & N/A & N/A \\
\hline
\end{tabular}

Note. $\mathrm{SA}=$ Strong statement or example suggesting agreement.

$\mathrm{A}=$ Indicate agreement (i.e., verbal or nonverbal).

*Indicate dissent (i.e., verbal or nonverbal), strong statement or example suggesting dissent.

$\mathrm{NR}=$ Nonresponse.

N/A = Not an applicable theme in the context of the focus group.

extent of agreement, disagreement, and nonresponse in each focus group. For each theme, the table reports the number of participants who either verbally or nonverbally (e.g., head nodding) expressed agreement with the importance of the theme and the number of participants who had nothing to say or indicate (nonverbally) about the theme. Asterisks in the table represent participants who either verbally or nonverbally expressed a dissenting viewpoint regarding a theme (e.g., shook heads in disagreement). What follows is a discussion of the findings in the table, theme by theme.

\section{Kelton-Based Themes ${ }^{4}$}

Accuracy

Kelton et al. (2008) define accuracy as "the extent to which information is free from error" (p. 370). Findings indicate that the study participants consistently and strongly conceptualized trustworthiness in terms of accuracy. Across the three focus groups, 15 of 22 participants either made strong statements in support of this theme or expressed agreement.

When asked what adjectives participants would use to describe a document they thought was trustworthy, both

\footnotetext{
${ }^{4}$ The concepts Kelton et al. (2008) propose as components of trustworthiness are closely related (e.g., accuracy, believability, and validity). As a result, in any individual response there was a range of ambiguity among the concepts. However, analysis of the complete data set suggests that the potential ambiguity of any individual response was not so great that it compromised the ability to distinguish patterns among responses; the average use of the concepts that comprise the Kelton-based themes as articulated by the study participants conforms to the specific definitions of the concepts as Kelton et al. define them. Some of the direct quotations used to support the Kelton-based themes in this paper vary in their ambiguity among other Kelton-based themes, but considering the entire data set, there were no established patterns of misuse or ambiguities for any particular theme.
}

FG1-S3 and FG1-S4 said, "accurate." In addition, FG1-S3 and FG1-S4 provided examples suggesting that they conceptualize inaccurate information as untrustworthy information. For example, FG1-S3 stated, "I think that maybe like relatives that have been married six times might put that they're Miss somebody or other, but that's according to them at the time. That's where mine would be untrustworthy of it." Hence, according to FG1-S3, a woman who has been married six times and reports that she is a Miss would be reporting incorrect information about her marital status, rendering that information untrustworthy. Similarly, FG1-S4 cited an example of a census record with incorrect names given, concluding that the information is untrustworthy:

According to the census ... the Prince of Wales and his wife the Princess lived in ... Washington. Did y'all know that? (laughter). They did. They were local Indians and they used their (gestures air quotes) "white man" names because this was a white man thing, to be in the census. So, you don't trust the information, but that's what the record says, so....

The fact that the census record lists the former Prince and Princess of Wales as residents of Washington is inaccurate, which, according to FG1-S4, makes that information untrustworthy.

\section{Believability}

Kelton et al. (2008) define believability as "the extent to which the information appears to be plausible" (p. 370). Kelton also treats believability as synonymous with credibility, which is consistent with other researchers who have conducted extensive research on credibility (Tseng \& Fogg, 1999; Fogg, 2003). Findings indicate that participants in the three groups collectively have weak support for believability 
as an element of trustworthiness, although the expressed support was quite strong. Two of the three groups offered almost no expression of support, while group two seemed to support the relevance of the term.

Evidence of participants' conceptualization of trustworthiness in terms of believability or credibility is deeply tied to the extent to which a concrete association can be made between the digitized document available in WADA and the physical source documents stored in archival warehouses. During the second focus group, FG2-S2 revealed her credibility conceptualization of document trustworthiness as she explained her process for formulating trustworthiness perceptions:

My first impression, in a split second, 'cause we do these things in milliseconds, is that if I see an original document, the very first thing is I give it a great deal of credibility before I read it. ... And then I judge it accordingly, but I think, just because I have an original document means a whole lot more to me, and I give it a great deal of credibility. If it's the only thing I have, I give it tremendous credibility, 'cause sometimes you can't compare it to anything.

For FG2-S2, the fact that a WADA document is a digitized copy of an original physical document is sufficient grounds for perceiving it as highly credible. As FG2-S2 made this statement, FG2-S1, FG2-S3, and FG2-S6 nodded their heads in agreement (kinesic) with FG2-S2, suggesting consensus among multiple participants in the focus group regarding a credibility document trustworthiness conceptualization.

\section{Coverage}

Kelton et al. (2008) define coverage as "the completeness of the information" (p. 370). Findings indicate weak support for the term. For two of the three interview groups, "coverage" or its associated term "completeness" played no role in the discussion. During the second focus group, two participants provided strong statements in support of this theme, two expressed agreement, and the remaining three did not provide a response. For example, the following interaction among the focus group participants shows the emergence of this theme:

Moderator-How would you describe a document you found using WADA that you think is trustworthy? Like, what adjectives would you use?

FG2-S6-Complete.

FG2-S2 - (Nods head in agreement) Yeah, yeah. Complete.

Moderator-So, if some of that information was not there, or if it was (points at FG2-S6 and then turns back to FG2-S2) incompleteFG2-S2-(Nods head in agreement) Correct.

Moderator-Then you would think that that document is not trustworthy?

FG2-S2-Not perhaps as trustworthy were it complete.

In the preceding passage, FG2-S6 and FG2-S2 both state that they would use the adjective "complete" to describe a document that they think is trustworthy, suggesting that they conceptualize document trustworthiness in terms of completeness. As a result of the moderator's probing question, it becomes clear that the participants' document trustworthiness perception in terms of completeness is not binary, but continuous. For example, it was FG2-S2 who remarked that the more complete a document is, the more trustworthy she perceives it. Evidence that other participants shared a similar conceptualization came from FG2-S3 who nodded his head in agreement (kinesic) with FG2-S2.

\section{Currency}

Kelton et al. (2008) define currency as "the degree to which the information is up-to-date rather than obsolete" ( $p$. 370). None of the participants mentioned currency during the focus groups.

\section{Objectivity}

Kelton et al. (2008) define objectivity as "balance of content" (p. 370). Findings provide minimal support for conceptualizing trustworthiness in terms of objectivity. During the third focus group, only one participant provided a statement in support of this theme, two participants expressed agreement using nonverbal communication, and the remaining five participants did not provide a response. Specifically, FG3-S3 mentioned the importance of questioning the bias that might be inherent in WADA document content, just as she suggested one must do for news information encountered on a daily basis:

It's like looking at the news today ... on the web. . . You have to question the bias or how the person, that person, got the information. I think that the document, like I keep saying, I trust that the document on the archive is as presented and is the true document. The facts in the document, I may not always trust.

FG3-S3 suggested that one must consider the bias in WADA document content even if she or he considers the document trustworthy in terms of it being the document that it claims to be. Thus, FG3-S3 drew a distinction between document trustworthiness and document content trustworthiness such that a document can be perceived as trustworthy while its content can be perceived as untrustworthy in terms of bias. Evidence that other participants shared a similar conceptualization came from FG3-S1 and FG3-S2, who both nodded their heads in agreement (kinesic) with FG3-S3.

\section{Stability}

Kelton et al. (2008) define stability as implying that "the information is persistent, in both its presence and its contents" (p. 370). In particular, they define stability as being insusceptible to alteration. Findings provide some indication that the study participants conceptualized trustworthiness in terms of stability. During the first focus group, one 
participant provided a statement in support of this theme while the remaining six participants did not provide a response. During the third focus group, three participants provided strong statements in support of this theme, one participant expressed agreement using nonverbal communication, and four participants did not provide a response. For example, during the first focus group, FG1-S4 asked, "Are you hinting to think it was doctored up or something?," in response to the moderator's question about whether anyone had ever questioned the trustworthiness of a WADA document. FG1-S4's question about what the moderator meant by trustworthiness indicated that one way she conceptualized trustworthiness was in terms of whether or not a document has been altered. During the third focus group, FG3-S6 stated that she would never suspect that WADA would alter one of its documents:

I just cannot see [WADA staff] falsifying documents, because this is like their breathing and everything else like that. So I just know the integrity I feel is so high in anyone who's in [the] archival [profession], because [they]'re not in it for the money, and [they]'re not in it for anything other than to really try to share all that [they] can gather and put in [the digital archives] and such like that.

FG3-S6's perceived integrity of WADA staff and the archival profession in general removed all doubt for her that any document she finds would be altered and therefore unstable due to tampering.

\section{Validity}

Kelton et al. (2008) define validity as "the use of responsible and accepted practices" such as "the soundness of the methods used, the inclusion of verifiable data, and the appropriate citation of sources" (p. 370). Findings suggest that participants conceptualized trustworthiness in terms of validity. During the second focus group, three participants provided strong statements in support of this theme and two participants expressed agreement via nonverbal communication. During the third focus group, two participants provided statements in support of this theme, while the remaining six participants did not provide a response.

For example, during the third focus group, FG3-S2 asked, "is it valid?" to describe how she would define document trustworthiness. In another example, FG2-S5 articulated her validity conceptualization of trustworthiness by explaining that a document is still trustworthy regardless of whether its content is accurate:

Even [with] a document, an original document, the person that wrote the information on it could have misheard or got distracted or whatever. I mean that information can be wrong, but it's still a valid document. But the information, which is a separate thing, could be incorrect.

According to FG2-S5, the person recording the information could have been the appropriate person, and could have been
TABLE 2. Team ratings for trustworthiness attributes.

\begin{tabular}{lccc}
\hline Attribute & Important & Somewhat Important & Not Important \\
\hline Accuracy & 7 & 0 & 1 \\
Validity & 7 & 1 & 0 \\
Coverage & 5 & 2 & 1 \\
Believability & 4 & 2 & 2 \\
Currency & 4 & 2 & 2 \\
Stability & 4 & 1 & 3 \\
Objectivity & 3 & 1 & 4 \\
\hline
\end{tabular}

receiving the information from the appropriate source. Hence the document was created using responsible and accepted practices. And yet, that person could have also misheard or got distracted, and as a result, recorded the information inaccurately. In other words, according to FG2S5, the document would still be valid because the appropriate person recorded the information from the proper source, even if the person recorded the information in error.

\section{Card-sorting Exercise Results}

The research questions were also addressed with cardsorting exercises in which participants grouped each of Kelton's trustworthiness attributes in terms of perceived importance. Participants broke into pairs or trios and grouped each of Kelton's trustworthiness attributes into one of three categories: important, somewhat important, or not important. In total, there were eight teams: three teams in the first focus group, two teams in the second focus group, and three teams in the third focus group. Table 2 lists each of Kelton's trustworthiness attributes and the number of teams that rated each attribute as important, somewhat important, and not important in terms of document trustworthiness. The presentation is ordered from most to least important.

Findings from the card-sorting exercises indicate that accuracy and validity are most central to users' conceptualization of trustworthiness (seven out of eight teams rated accuracy and validity as important in terms of trustworthiness at the document level), followed by coverage (five out of eight teams rated coverage as important in terms of trustworthiness at the document level). Four teams rated believability, currency, and stability as important in terms of trustworthiness at the document level. In contrast, only three out of eight teams rated objectivity as important in terms of trustworthiness at the document level.

\section{Emergent Themes}

\section{Authenticity}

One way participants conceptualized the trustworthiness of a document was in terms of its perceived authenticity. In each focus group, participants articulated this particular conceptualization in the form of a question. For example, during the second focus group, FG2-S5 asked, "it could have been 
fake? Is that what you're suggesting or asking?," and during the third focus group, FG3-S2 said, "now, if you're asking, is that a forgery?" These participants' questions about what the moderator meant by the term trustworthiness suggest that they conceptualized trustworthiness in terms of a document's perceived authenticity, that is, is it fake?

All of the participants said "no," "m-m," and/or shook their heads in disagreement (kinesic) to indicate that they had never questioned the trustworthiness of an archival document delivered digitally. In addition, participants made statements in support of this theme, including FG1-S3 who remarked, "I don't think I ever would question it. I mean, the actual, that that's not the real thing." FG1-S6 added, "it may not be the one I'm looking for, but they're all the real thing." When the moderator asked why as a follow-up question, participants' responses indicated that they were considering an authenticity conceptualization of trustworthiness. FG1-S6 responded, "the records are so old that it seems silly to have a fake one in there." When the moderator asked why as a follow-up question, FG2-S5 asked, "why would we think it was a fake?" In a similar discussion during the third focus group, FG3-S4 responded, "I would think they'd be the real documents," expressing her authenticity conceptualization of trustworthiness.

\section{Inaccurate Information}

Our findings suggest that participants conceptualized documents as trustworthy despite containing inaccurate information, although discussion of this attribute of trustworthiness elicited both strong agreement and strong disagreement within one focus group. During the first focus group, two participants provided strong statements in support of this theme, while the remaining five did not provide a response. During the second focus group, three participants provided strong statements in support of this theme, one expressed agreement using nonverbal communication, one provided a statement representing a dissenting viewpoint, and the remaining two did not provide a response. During the third focus group, four participants provided statements in support of this theme, two provided strong statements expressing a dissenting viewpoint, and the remaining two did not provide a response. In terms of support, during the second focus group, FG2-S1 described an example of a census record that included inaccurate information about her parents' places of residence:

The 1940 census that just came out. . . So you look on there and over where it says where you lived and everything, my Mother's information and my Father's information is reversed, because my Father was at college in Pullman, and my Mother was living in (inaudible) I think. But when you look on the census, written right on there, it says that she was in Pullman and he was in (inaudible) Washington, so actual document, should be $100 \%$ correct, you know. ... And so the document is accurate. I mean, it's a census record, but the actual information is erroneous.
Despite the fact that the information in the census record was inaccurate (FG2-S1's parents' places of residence were reversed), she considered the document trustworthy because it was still a census record even though it lacked verisimilitude.

Throughout the third focus group, participants expressed consenting and dissenting viewpoints on the inaccurate information theme. For example, FG3-S2 recounted an instance in which she was using a death record to find information about one of her relatives' parents, only to discover the information on the death record contained inaccurate information, which negatively impacted her document trustworthiness perception:

I was hoping to find the names of the parents for this person who died, and it gave the name of the adopted father- not the birth father-and the only way I knew that that wasn't the right one, the right information, was [because] my husband, who is the expert on the family, said, "oh no, she was adopted. She was born before that marriage happened." So you have to have a knowledge base of your own about the family you're researching to know sometimes whether the document you're looking at is trustworthy.

In contrast, FG3-S1 responded to FG3-S2's statement, suggesting that the document was still trustworthy, despite containing inaccurate information about FG3-S2's relative's birth father, because it was a convention of the time period to list adopted parents as birth parents in birth and death records:

According to the records, that is correct, because, at that time, almost all adoptions were closed, and all record of the previous was wiped off the records. A lot of the true birth certificates were destroyed.

\section{Primary or First-hand Evidence}

Participants conceptualized trustworthiness as the extent to which a document is primary or first-hand. In particular, participants suggested that first-hand or primary documents are more trustworthy than second-hand or other documents. Participants defined primary documents as documents that were written during the time period of the events that they were about as opposed to documents that serve as accounts of what happened that were written at a later time. Other participants defined primary or first-hand as having been written by the actual person(s) the documents were meant to represent. The assumption underlying the high value participants placed on primary documents is that, the closer the document is to the original or the actual event, the less likely the error or the less likely important information has been omitted, changed, or otherwise altered.

During the first focus group, four participants provided responses suggesting the importance of a document being first-hand or primary, with the remaining three not providing any response. During the second focus group, five 
participants indicated that primary sources are more trustworthy than secondary sources or other sources, with the remaining two not providing any response. During the third focus group, four participants indicated that primary sources are more trustworthy than secondary sources or other sources, with the remaining five not providing any response. The following passage illustrates the emergence of this theme among five participants in the second focus group:

FG2-S1-To me, it's the closest to the source. Closest to the original (0.2) (gestures air quotes) "action" that happened.

FG2-S2-(Nods head in agreement) Yeah.

FG2-S1-If it's a birth, you want the hospital. And then you want maybe the doctor, and then, maybe, you know, a neighbor, and maybe a census record. If it's a marriage, you want the marriage document, and then maybe the listing in the book that says, they were married on this date, and then maybe a diary that says they were married, you know. So it's the closest document to the action, is the most trustworthy.

FG2-S4-I think it's the document versus maybe say a ledger. You know when you've got a ledger of, you know, Suzy had married, and you know, it's just this big long ledger, whereas, where FG2-S1 is saying, it's from a hospital, or the doctor, you know, it's maybe a little bit more trustworthy because whoever is doing the ledger is getting the information second- or third-hand.

FG2-S5-(Nods head in agreement).

FG2-S1-The less times it's transcribed-

FG2-S5-(Nods head in agreement) (overlapping) Right.

FG2-S4-(Points at FG2-S1) Yes.

FG2-S3 - (Nods head in agreement and smiles).

FG2-S1 - the less chance there is to have-

FG2-S5-(Overlapping) Every time it's recopied or recopied or recopied.

FG2-S1-An error in transcription.

In the preceding passage, participants used two chronemic expressions for emphasis and eight kinesic expressions to either draw contrasts or indicate agreement. For example, FG1-S1 used two chronemic expressions to draw attention to the idea that the closer a document is to the actual event that happened, the more trustworthy she perceives it. Specifically, FG2-S1 took a two-second pause before saying "action," and she said "action" slower than the other words in her statement to draw attention to the fact that a document's proximity to the action it is about is what influences her trustworthiness perceptions. While pausing, FG2-S1 used hand gestures to put "action" in quotes to further emphasize the importance of a document's proximity to the action it is about on her trustworthiness perception. In the passage above, the most common kinesic expressions were to indicate agreement with what others were saying. For example, throughout the passage, FG2-S2, FG2-S3, and FG2-S5 nodded their heads in agreement with statements FG2-S1 made about the influence of how primary a document is on her trustworthiness perception. FG2-S4 even pointed at FG2-S1 and said "yes," to indicate agreement with one of her statements.
The other use of kinesic expressions during this passage was to illustrate the distinction among primary, secondary, and tertiary sources. Specifically, FG2-S1, FG2-S2, and FG2-S5 all talked about the difference between primary and other sources, and when they did, they made hand gestures closer to themselves when talking about primary sources and deliberately made hand gestures further away from themselves when discussing what they considered secondary or tertiary sources. For example, when FG2-S4 said that he would consider a document more trustworthy than a ledger because, according to him, "whoever is doing the ledger is getting the information second- or third-hand," he made hand gestures closer to himself when talking about documents and further away from himself when talking about ledgers. Similarly, when FG2-S4 said "every time it's recopied or recopied or recopied" she twirled her left hand each time she said recopied, and each time she moved her twirling left hand further away from herself to spatially draw the distinction among primary, secondary, and tertiary instantiations of a document as she was talking.

Primary documents, as described by the focus group participants, are indeed the very archival records that are digitized and delivered through WADA. In focusing on documents instead of the collections of records represented by WADA, participants voiced the value they placed on digital access to the archival record and the important role that "primary" played in their conception of trustworthiness.

\section{Document Legibility or Readability}

Another way participants conceptualized trustworthiness was in terms of a document's legibility or readability. In multiple focus groups, participants articulated this particular conceptualization in the form of a question. For example, during the first focus group, FG1-S4 asked, "trustworthiness, can I read it?," and during the third focus group, FG3-S2 asked, "by the word trustworthy, do you mean that they're readable? Or, you know, that they're visually trustworthy?" These participants' questions about what the moderator meant by the term trustworthiness suggest that they conceptualized trustworthiness in terms of a document's legibility or readability.

Evidence that other participants besides FG1-S4 and FG3-S2 also conceptualized trustworthiness in terms of legibility or readability came from participants' responses to one of the moderator's prompts, which asked participants to describe a document from WADA that they thought was trustworthy. During the first focus group, FG1-S4 replied, "[r]eadable, as in filmed properly" (by filmed properly, FG1-S4 was referring to digitization). In essence, FG1-S4 conceptualized trustworthiness as a well-digitized, and therefore readable, document. None of the other six participants in FG1-S4's focus group provided a response to her description of a trustworthy archival document delivered digitally as one that is readable. In the second focus group, one participant made a statement about her 
conceptualization of trustworthiness in terms of legibility, one expressed agreement, one dissented with this point of view, and the remaining four participants did not provide a response. During the third focus group, one participant made strong statements about her conceptualization of trustworthiness in terms of readability, three displayed nonverbal expressions to indicate agreement, and the remaining five did not provide a response. The following passage illustrates the emergence of this theme along with the consensus and dissention it caused in the context of the second focus group:

FG2-S1-I was going to say, I think an important thing is legibility. Moderator-Okay. For the document as a document?

FG2-S1-Yes, because if it's, you know, a real fuzzy reproductionFG2-S3-(Overlapping) oh yeah. (nods head in agreement).

FG2-S1-Or the original was, what, the ink bled and things like that, and then the reproduction isn't really clear, what you read on, that could be-

FG2-S5-No, now you're talking about the information though. It's still a document even though it got run over by a train.

In the preceding passage, FG2-S1 articulated her conceptualization of trustworthiness in terms of a document's legibility. The moderator asked for clarification as to whether FG2-S1's conceptualization was specific to the document or the document content. FG2-S1 confirmed that her conceptualization of trustworthiness referred specifically to document trustworthiness, and then gave an example of reduced legibility as a result of poor digitization, to which FG2-S3 responded by nodding his head in agreement (kinesic). FG2-S5 dissented with this conceptualization of trustworthiness. According to FG2-S5, whether or not a document is more or less legible does not make it more or less trustworthy.

\section{Proper Form}

Another way participants conceptualized document trustworthiness was in terms of a document's perceived proper form. During the second focus group, five participants provided strong statements in support of this theme, one expressed agreement, and the remaining individual did not provide a response. The following interaction among the focus group participants shows the emergence of this theme:

FG2-S2-I can't imagine anybody not believing that a document wouldn't be trustworthy in that millisecond that you see it's an actual picture of that document.

FG2-S6-And that means you would have to be familiar with what the original-

FG2-S3-(Nods head in agreement).

FG2-S6-document should look like.

FG2-S3 - Exactly. (nods head in agreement).

FG2-S2 - Well, yeah you'd have to, but I think most people figure that, even in a millisecond, you have a feeling of what an official document should look like.

FG2-S6-(Nods head in agreement) Yeah.
FG2-S1-You want it to have the proper form-

FG2-S3-(Overlapping) You have some image of it. Yeah, that there would be a proper form.

\section{Discussion}

The goal of this study was to understand how actual users conceptualize trustworthiness for archival documents delivered digitally, and to understand the extent to which an existing conceptual framework could be useful for capturing this understanding. Our findings suggest that, to varying degrees and with varying levels of emphasis, users conceptualize document trustworthiness in terms of accuracy, authenticity, believability, coverage, currency, first-hand or primary nature, form, inaccurate information (depending on the context), legibility, objectivity, stability, and validity. No single facet dominates the discussion of what it means to a user for a document to be trustworthy, although there was more support for some conceptualizations than others.

This study can be used to suggest that, while Kelton et al.'s (2008) Integrated Model of Trust in Information is a viable tool for driving empirical research, their framework for "trustworthiness" should be rethought and made more measurable in the context of archival documents delivered through a digital repository. The study captured strong evidence that users, variously, conceptualized trustworthiness in terms of perceived accuracy, believability, coverage, currency, objectivity, stability, and validity. The evidence suggests that the Kelton model, in particular the general concept of Trustworthiness, is useful for understanding user perception of the overall value of documents delivered in a digital repository context. This is good news for the Kelton model as a whole, because it demonstrates the importance of trustworthiness in a general model of trust in preservation. Although useful, Kelton's model does not provide an adequate picture of the study participants' conceptualizations of document trustworthiness. For example, additional conceptualizations having to do with a document's firsthand nature, legibility, and form uncovered during the study are also important pieces of participants' conceptualizations of trustworthiness not captured in Kelton's model.

This study also suggests that users of archival documents delivered digitally conceptualized trustworthiness in ways not unlike how some archival scholars of authenticity and reliability (Duranti, 1995; MacNeil, 2000; Duranti et al., 2008) conceptualize the phenomenon. In particular, findings from this study suggest that participants conceptualized trustworthiness at the document level in terms of authenticity, and were able to articulate what they meant by the term in ways that mirror more theoretical conceptions in the archival literature. Our findings also indicate that study participants conceptualized trustworthiness at the document level in terms of reliability, and seemed to have an innate grasp of the practical implications of confronting digitized archival records that are and are not reliable.

Findings from this study also suggest that users of archival documents delivered digitally conceptualized 
TABLE 3. Document trustworthiness conceptualizations in order from most to least important.

\begin{tabular}{lc}
\hline $\begin{array}{l}\text { Document Trustworthiness } \\
\text { Conceptualization }\end{array}$ & $\begin{array}{c}\text { Number of Strong } \\
\text { Statements (SAs) }\end{array}$ \\
\hline Authenticity & 12 \\
Accuracy & 11 \\
Inaccuracy/trustworthy & 9 \\
First-hand & 9 \\
Believability & 5 \\
Validity & 5 \\
Form & 5 \\
Stability & 4 \\
Legibility & 3 \\
Coverage & 2 \\
Objectivity & 1 \\
Currency & 0 \\
\hline
\end{tabular}

trustworthiness differently from how Duranti (1995), MacNeil (2000), and Duranti et al. (2008) conceptualize the construct. For example, study participants conceptualized trustworthiness at the document level in terms of a document's currency, objectivity, and readability. Depending on the context, participants also conceptualized inaccurate information as trustworthy, all of which are conceptual departures from Duranti, MacNeil, and Duranti et al.

There were three main advantages of using microinterlocutor analysis for a study of trustworthiness. First, analyzing participants' chronemic, paralinguistic, and kinesic expressions with the verbal data pertaining to the themes permitted capture of "the voices" of those participants who did not make verbal statements in support of the themes, but appeared to agree or disagree with them. Second, micro-interlocutor analysis was useful for identifying those trustworthiness conceptualizations that seemed to be more important to users than others. For example, it afforded the opportunity to rank-order trustworthiness conceptualizations by how many strong statements (SAs) participants made in support of the conceptualizations (Table 3). Using this analysis strategy, authenticity-as understood and articulated by the participants-was the most important document trustworthiness conceptualization, followed by accuracy, inaccurate/trustworthy, firsthand, believability, validity, form, stability, legibility, coverage, objectivity, and currency. Third, microinterlocutor analysis provided rich data about dissenting viewpoints, even though dissent was relatively rare in this study. Nevertheless, dissent enriched the data so that it was more amenable to ranking themes that have the same number of SAs but different numbers of participants who expressed: agreement verbally or nonverbally (As), disagreement verbally or nonverbally $\left({ }^{*} s\right)$, or statements of dissent $(* s)$. However, caution should be used in interpreting ranked lists of themes using micro-interlocutor analysis results, particularly when nonresponse is high, as there is no way to determine how the nonrespondents felt about those themes.
It was important to ask general questions about trustworthiness (Part 1) during the focus groups and also conduct card-sorting exercises (Part 2) because each component of the interview process revealed important information about participants' conceptualizations of document trustworthiness that would not have been captured otherwise. For example, during Part 1, none of the participants mentioned currency with respect to document trustworthiness, and yet, during the card-sorting exercises, half of the pairs/trios ranked currency as important in terms of document trustworthiness perception. Also, as noted earlier, participants' responses revealed additional conceptualizations of document trustworthiness beyond those in Kelton et al. (2008), Duranti (1995), MacNeil (2000), and Duranti et al. (2008). Overall, this study confirms the general trends in the research literature that trustworthiness at the document level has multiple components, some of which are potentially multifaceted. Asking questions about each of those facets is necessary to fully grasp document trustworthiness in terms of user perception.

This study has three primary limitations: one regarding the assistant moderators, one regarding the discussion preceding the card-sorting exercises, and one regarding the issue of saturation. First, Krueger (1998) states that every focus group should have both a moderator and an assistant moderator, and that the moderator should carefully select the assistant moderator. The moderator used the same assistant moderator for the first and second focus group and a different assistant moderator for the final focus group. Both assistant moderators were employees of the Washington State Archives. In retrospect, having Washington State Archives staff members serve as assistant moderators may not have been the best choice. After learning about the assistant moderators' employment statuses, participants asked them questions that had nothing to do with the goals and purposes of the focus groups. The moderator had to actively restate the purpose of the focus group and inform the participants that they could ask the assistant moderators questions not pertaining to the focus groups after they were over. To a certain extent, the assistant moderators served as distractions and took valuable time away that could have been better utilized for the purpose of collecting more data about participants' trustworthiness conceptualizations. In addition, participants could have been withholding information about how they really felt about WADA documents and their trustworthiness conceptualizations of them because they were aware that WADA staff were present, another potential detrimental side effect of using WADA staff as assistant moderators.

Second, there is a possibility that the discussion preceding the card-sorting exercises tainted the results of the card sort. For example, some of the participants could have been influenced by the ways in which other participants articulated their conceptions of trustworthiness, which, in turn, could have affected how they sorted the cards. There is no way to know the extent to which some participants were influenced by other participants' statements during the 
discussion. What is certain is that during the discussion the moderator neither provided a definition of trustworthiness nor provided definitions or otherwise mentioned the components of trustworthiness in the Kelton model.

The third limitation regards the issue of saturation. Some researchers refer to saturation as the point at which themes reoccur and no additional information regarding previously identified themes surfaces. Applying the concept to analysis of focus group data, Krueger and Casey (2009) state (p. 21):

The accepted rule of thumb is to plan three or four focus groups with each type or category of individual. Once you have conducted these first three or four groups, determine if you have reached saturation. Saturation is a term used to describe the point where you have heard the range of ideas and aren't getting new information. If after three or four groups you were still getting new information, you would conduct more focus groups. The reason you plan three to four groups is that focus groups are analyzed across groups. The analyst looks for patterns and themes across groups.

Thus, if the same type of data regarding all of the themes had been collected during all three focus groups, a claim for saturation, as defined in Krueger and Casey (2009), would have been substantiated for this study. Further, Table 1 could be used to demonstrate reaching a point of saturation. For example, for Authenticity, Inaccurate/Trustworthy, Firsthand/Primary, Legibility/Readability, Accuracy, and Believability, participants gave similar statements, such that the themes were reoccurring; no new information was collected (see Table 1). Had this been the case for all of the themes under investigation, a claim of saturation could be substantiated for this study.

In actuality, for some of the themes under investigation, data were not collected during all three focus groups. And for other themes, data were not collected until the third focus group, indicating collection of new information, which would suggest that a saturation point had not been reached. For example, data collected regarding Stability and Validity did not consistently emerge across all three focus groups (Table 1). Data pertaining to Stability emerged during the first and the third focus groups, but not the second focus group. Similarly, data pertaining to Validity emerged during the second and the third focus groups, but not the first focus group. In order for a claim of saturation to be substantiated, as defined by Krueger and Casey (2009), data regarding Validity and Stability would needed to have emerged during all three focus groups. The collection of data regarding the theme Objectivity is perhaps why a claim for saturation is least able to be substantiated, as defined by Krueger and Casey (2009). No data regarding this particular theme were collected until the third focus group; this would suggest that new information was obtained during the last focus group, and thus additional focus groups needed to be conducted. Although collecting data regarding the Objectivity theme during the third focus group indicated that saturation had not been reached, thereby suggesting the need to conduct more focus groups in order to reach saturation, this would have been cost-prohibitive. The researchers lived in Michigan and the study participants lived in Washington. Conducting additional focus groups would have added additional days of hotel accommodations and/or multiple flights from Michigan to Washington, which would have pushed costs far beyond the project budget, which had already been finalized.

Another approach to saturation recommended for focus group data involves theoretical sampling (Charmaz, 2006; Liamputtong, 2011). In order to substantiate a claim for saturation for this study using the theoretical sampling technique, one focus group would have been conducted, the resulting data transcribed, analyzed, themes identified, and the analysis would have guided the subsequent focus group. Before conducting the next focus group, the focus group guide would have been modified to include questions that would enable the development of themes that emerged from data from the previous focus group. This iterative process of collecting and analyzing data would have persisted until "gathering fresh data no longer spark[ed] new theoretical insights, nor reveal[ed] new properties" of the themes that were identified (Charmaz, 2006, p. 113). By following the theoretical sampling technique common in grounded theory (Charmaz, 2006), and applying it to the analysis of focus group data (Liamputtong, 2011, p. 45), a claim of saturation could have been substantiated in the context of this study. Unfortunately, applying the theoretical sampling technique as a means of operationalizing saturation would have been time- and therefore cost-prohibitive.

\section{Conclusion}

This study makes several contributions to understanding uses of the expanding universe of documentation in digital form. In terms of research on digital curation, it focuses on users' definition of trustworthiness at the document level instead of the more common work done on trust at the digital repository level. The study also advances the notion of a designated community by conducting research on a sample of a specific designated community that stakeholders of a digital repository acknowledge is a primary audience. It also contextualizes and extends Flanagin and Metzger's (2008) definition of trustworthiness for a specific user group (genealogists) who utilize certain types of archival documents from a digital repository; the study provides a more specific definition of trustworthiness derived from user experience.

The study examines and tests the principal component of a relatively new but important conceptual frameworkKelton et al.'s Integrated Model of Trust in Information-by interrogating the appropriateness of the model to fit a certain scenario, that of end users with extensive experience using archival documents delivered digitally from a specific trusted repository. The study calls into question one of the constructs in the model, Trustworthiness, finding that some of its dimensions are relevant, while others are not. This study makes a methodological contribution to the 
information science community by being the first to apply micro-interlocutor analysis to focus group data. This study also demonstrates that micro-interlocutor analysis provides a realistic picture of the strength and character of emergent themes that underpin the more general concept of trustworthiness.

\section{Future Research}

One of the primary values of focus group research is to learn how participants talk about a construct, which could, in turn, "facilitate the design of questionnaires, survey instruments, or other research tools that might be employed in more quantitative research" (Stewart et al., 2007, p. 42). Findings from this study will be used to create survey items in pursuit of scale to measure user document trustworthiness perception in a preservation context. Specifically, the survey measurement items will be derived from participants' responses in this study and deployed in a survey instrument to a much larger sample of the same type of users who have similar types of information needs and use the same types of documents from one repository (e.g., a much larger sample of genealogists who utilize WADA documents). The results from such a study hold the promise of providing evidence on a much larger scale about what attributes comprise the important construct of trustworthiness and how to measure them.

\section{Acknowledgments}

This material is based upon work supported by a Graduate Student Research Grant from the Horace H. Rackham School of Graduate Studies at the University of Michigan. We would like to thank William Jacoby, James Lepkowski, Soo Young Rieh, and Elizabeth Yakel for providing feedback on previous drafts of this paper. We would also like to thank Terence S. Badger and the staff at the Washington State Digital Archives for their help and support.

\section{References}

Atkinson, R. (1996). Library functions, scholarly communication, and the foundation of the digital library: Laying claim to the control zone. The Library Quarterly: Information, Community, Policy, 66(3), 239-265.

Boyatzis, R.E. (1998). Transforming qualitative information: Thematic analysis and code development. Thousand Oaks, CA; Sage.

Braun, V., \& Clarke, V. (2006). Using thematic analysis in psychology. Qualitative Research in Psychology, 3, 77-101.

Charmaz, K. (2006). Constructing grounded theory: A practical guide through qualitative analysis. London: Sage.

Consultative Committee for Space Data Systems. (2002). Reference model for an open archival information system (OAIS) recommendation for space data system standards; blue book. Washington, DC: CCSDS Secretariat. http://public.ccsds.org/publications/archive/650x0b1s.pdf

Duff, W., Craig, B., \& Cherry, J. (2004). Finding and using archival resources: A cross-Canada survey of historians studying Canadian history. Archivaria, 58, 51-80.

Duff, W.M., \& Johnson, C.A. (2003). Where is the list with all the names? Information-seeking behavior of genealogists. American Archivist, 66(1), 79-95.
Duranti, L. (1995). Reliability and authenticity: The concepts and their implications. Archivaria, 39, 5-10.

Duranti, L. (2009). From digital diplomatics to digital records forensics. Archivaria, 68(Fall), 39-66.

Duranti, L., Suderman, J., \& Todd, M. (2008). A framework of principles for the development of policies, strategies and standards for the long-term preservation of digital records. In L. Duranti \& R. Preston (Eds.), International research on permanent authentic records in electronic systems (InterPARES) 2: Experiential, interactive and dynamic records (pp. 661-683). Retrieved from: http://www.interpares.org/ display_file.cfm?doc=ip2_book_complete.pdf

Fincher, S., \& Tenenberg, J. (2005). Making sense of card sorting data. Expert Systems, 22(3), 89-93.

Flanagin, A.J., \& Metzger, M.J. (2000). Perceptions of internet information credibility. Journalism and Mass Communication Quarterly, 77(3), 515540.

Flanagin, A.J., \& Metzger, M. (2008). Digital media and youth: Unparalleled opportunity and unprecedented responsibility. In M.J. Metzger, \& A.J. Flanagin (Eds.), Digital media, youth, and credibility (pp. 5-28). Cambridge, MA: MIT Press.

Fogg, B.J. (2003). Persuasive technology: Using computers to change what we think and do. Amsterdam, Boston: Morgan Kaufmann Publishers.

Gladney, H.M. (2009). Long-term preservation of digital records: Trustworthy digital objects. American Archivist, 72(2), 401-435.

Guest, G., MacQueen, K.M., \& Namey, E.E. (2012). Applied thematic analysis. Thousand Oaks, CA: Sage.

Hedstrom, M., \& Lee, C. (2002). Significant properties of digital objects: Definitions, applications, implications. Proceedings of the DLM-Forum 2002, Parallel Session 3, Washington, DC: Digital Library Federation, 218-223.

Hedstrom, M., Lee, C., Olson, J., \& Lampe, C. (2006). "The old version flickers more": Digital preservation from the user's perspective. American Archivist, 69(1), 159-187.

Henry, G. (2012). Core infrastructure considerations for large digital libraries. Washington, DC: Council on Library and Information Resources.

Hilligoss, B., \& Rieh, S.Y. (2008). Developing a unifying framework of credibility assessment: Construct, heuristics, and interaction in context. Information Processing \& Management, 44(4), 1467-1484.

International Organization for Standardization. (2012). Space data and information transfer systems: Audit and certification of trustworthy digital repositories [Systèmes de transfert des informations et données spatiales: audit et certification des référentiels numériques de confiance] (1st ed.). Geneva, Switzerland: International Organization for Standardization.

Kelton, K., Fleischmann, K.R., \& Wallace, W.A. (2008). Trust in digital information. Journal of the American Society for Information Science and Technology, 59(3), 363-374.

Knight, S. (2008). User perceptions of information quality in World Wide Web information retrieval behaviour. Doctoral Dissertation, Perth, Australia: Edith Cowan University, 1-362.

Krueger, R.A., \& Casey, M.A. (2009). Focus groups: A practical guide for applied research. Los Angeles: Sage.

Krueger, R.A. (1998). Moderating focus groups. Thousand Oaks, CA, London: Sage.

Liamputtong, P. (2011). Focus group methodology: Principles and practices. Los Angeles: Sage.

Lucassen, T., Muilwijk, R., Noordzij, M.L., \& Schraagen, J.M. (2013). Topic familiarity and information skills in online credibility evaluation. Journal of the American Society for Information Science and Technology, 64(2), 254-264.

Lucassen, T., \& Schraagen, J.M. (2011). Factual accuracy and trust in information: The role of expertise. Journal of the American Society for Information Science and Technology, 62(7), 1232-1242.

Lucassen, T., \& Schraagen, J.M. (2012). Propensity to trust and the influence of source and medium cues in credibility evaluation. Journal of Information Science, 38(6), 566-577.

Lynch, C. (2000). Authenticity and integrity in the digital environment: An exploratory analysis of the central role of trust. Authenticity in a Digital 
Environment (pp. 32-50). Washington, DC: Council on Library and Information Resources. Retrieved from: http://clir.org/pubs/reports/ pub92/pub92.pdf

MacNeil, H. (2000). Trusting records: Legal, historical and diplomatic perspectives. Dordrecht, London: Kluwer Academic.

MacNeil, H.M., \& Mak, B. (2007). Constructions of authenticity. Library Trends, 56(1), 26-52.

Meijer, A.J. (2003). Trust this document! ICTs, authentic records and accountability. Archival Science, 3(3), 275-290.

Metzger, M.J. (2007). Making sense of credibility on the web: Models for evaluating online information and recommendations for future research. Journal of the American Society for Information Science and Technology, 58(13), 2078-2091.

Metzger, M.J., Flanagin, A.J., \& Medders, R.B. (2010). Social and heuristic approaches to credibility evaluation online. Journal of Communication, 60(3), 413-439.

Morgan, D.L. (1997). Focus groups as qualitative research. Thousand Oaks, CA: Sage.

Onwuegbuzie, A.J., Dickinson, W.B., Leech, N.L., \& Zoran, A.G. (2009). A qualitative framework for collecting and analyzing data in focus group research. International Journal of Qualitative Methods, 8(3), $1-21$.

Price, D.M., \& Smith, J.J. (2011). The trust continuum in the information age: a Canadian perspective. Archival Science, 11(3-4), 253-276.

Research Libraries Group/Online Computer Library Center Working Group on Digital Archive Attributes. (2002). Trusted digital repositories: Attributes and responsibilities. Mountain View, CA: RLG. Retrieved from: http://www.oclc.org/research/activities/past/rlg/trustedrep/ repositories.pdf

Rieh, S.Y. (2002). Judgment of information quality and cognitive authority in the web. Journal of the American Society for Information Science and Technology, 53(2), 145-161.

Rieh, S.Y. (2010). Credibility and cognitive authority of information. Encyclopedia of Library and Information Sciences, 3rd ed. 13371344.

Rieh, S.Y., \& Danielson, D.R. (2007). Credibility: A multidisciplinary framework. Annual Review of Information Science and Technology, 41(1), 307-364.

Rieh, S.Y., Kim, Y., Yang, J.Y., \& St. Jean, B. (2010). A diary study of credibility assessment in everyday life information activities on the web: Preliminary findings. Proceedings of the American Society for Information Science and Technology, 47(1), 1-10.

St. Jean, B., Rieh, S.Y., Yakel, E., \& Markey, K. (2011). Unheard voices: Institutional repository end-users. College \& Research Libraries, 72(1), $21-42$.

Stewart, D.W., \& Shamdasani, P.N. (1990). Focus groups: Theory and practice. Newbury Park, CA: Sage.

Stewart, D.W., Shamdasani, P.N., \& Rook, D.W. (2007). Focus groups: Theory and practice. Thousand Oaks, CA, London, New Delhi: Sage.

Tseng, S., \& Fogg, B.J. (1999). Credibility and computing technology. Communications of the ACM, 42(5), 39-44.

Washington State Archives-Digital Archives. (2013). Background and history. Retrieved from: http://www.digitalarchives.wa.gov/ StaticContent/background

Waters, D., \& Garrett, J. (1996). Preserving digital information: Report of the Task Force on Archiving of Digital Information. Washington, DC: Council on Library and Information Resources.

Yakel, E. (2004). Seeking information, seeking connections, seeking meaning: Genealogists and family historians. Information Research, 10(1). http://informationr.net/ir/10-1/paper205

Yakel, E., Faniel, I., Kriesberg, A., \& Yoon, A. (2013). Trust in digital repositories. International Journal of Digital Curation, 8(1), 143156.

Yakel, E., \& Torres, D.A. (2007). Genealogists as a "community of records". American Archivist, 70(1), 93-113.

Yeo, G. (2010). "Nothing is the same as something else": Significant properties and notions of identity and originality. Archival Science, 10(2), 85-116.
Yeo, G. (2013). Trust and context in cyberspace. Archives and Records: The Journal of the Archives and Records Association, 34(2), 214-234.

Yoon, A. (2014). End users' trust in data repositories: Definition and influences on trust development. Archival Science, 14(1), 17-34.

Zhou, X. (2005, August). A comparison of users' response to digital versus physical archival material. Paper Presented at the Society of American Archivists Annual Meeting, New Orleans, LA, 1-11.

\section{Appendix A1}

\section{Focus Group Presurvey}

\section{Study Participants' Internet Usage}

Question 1: On average, how frequently do you use the Internet?

- Daily

- Weekly

- Monthly

- 1 or 2 times

Question 2: In general, I trust information I find on the Internet.

- Strongly Agree

- Agree

- Disagree

- Strongly Disagree

\section{Study Participants' WADA Usage}

Question 3: In the last year, how frequently have you used the Washington State Digital Archives?

- Daily

- Weekly

- Monthly

- 1 or 2 times

Question 4: What is your primary reason for visiting the Washington State Digital Archives?

- Business

- Genealogy

- Historical Research

- Local Government

- Other

Question 5: I usually find the documents I'm looking for when using the Washington State Digital Archives?

- Strongly Agree

- Agree

- Disagree

- Strongly Disagree

Question 6: How strongly do you trust the documents you find when using the Washington State Digital Archives?

- Trust very strongly

- Somewhat strongly

- Not very strongly

- Not at all

Question 7: How satisfied are you with the way the Washington State Digital Archives displays documents?

- Very satisfied

- Satisfied

- Dissatisfied

- Very Dissatisfied 


\section{Background Information}

Question 8: What is your age range?

- 19 or under

- 20 to 29

- 30 to 39

- 40 to 49

- 50 to 59

- 60 to 69

- 70 or older

Question 9: What is your gender?

- Female

- Male

\section{Appendix A2}

\section{Focus Group Guide}

Phase 1

1. Discuss the nature of the documents you use when using WADA and your purpose(s) for using them.
2. Discuss your perceptions of trustworthiness for the documents you find using WADA. Can you give an example of a document you found that you thought was trustworthy, or one that looks more trustworthy than typical documents you find in WADA?

3. How would you describe a document you found in WADA that you think is trustworthy? What adjectives would you use?

4. Under what circumstances would you question the trustworthiness of a document you encountered while using WADA?

Phase 2

5. Card-sorting exercise: Study participants break into pairs and sort the following trustworthiness attributes (accurate, believable, complete, current, objective, stable, and valid) into three piles in terms of how important they are for the WADA documents they use: important, somewhat important, and not important. After the pairs are done, discuss how and why each pair grouped the attributes the way they did. 